University of Nebraska - Lincoln

DigitalCommons@University of Nebraska - Lincoln

Biochemistry -- Faculty Publications

Biochemistry, Department of

December 1999

\title{
Biochemical and biophysical analysis of the intracellular lipid binding proteins of adipocytes
}

\author{
Melanie A. Simpson \\ University of Nebraska - Lincoln, msimpson2@unl.edu \\ Vince J. LiCata \\ University of Minnesota, St. Paul, MN, USA \\ Natalie Ribarik Coe \\ University of Minnesota, St. Paul, MN, USA \\ David A. Bernlohr \\ University of Minnesota, St. Paul, MN, USA
}

Follow this and additional works at: https://digitalcommons.unl.edu/biochemfacpub

Part of the Biochemistry, Biophysics, and Structural Biology Commons

Simpson, Melanie A.; LiCata, Vince J.; Ribarik Coe, Natalie ; and Bernlohr, David A., "Biochemical and biophysical analysis of the intracellular lipid binding proteins of adipocytes" (1999). Biochemistry -Faculty Publications. 17.

https://digitalcommons.unl.edu/biochemfacpub/17

This Article is brought to you for free and open access by the Biochemistry, Department of at DigitalCommons@University of Nebraska - Lincoln. It has been accepted for inclusion in Biochemistry -- Faculty Publications by an authorized administrator of DigitalCommons@University of Nebraska - Lincoln. 
Published in Molecular and Cellular Biochemistry 192 (1999), pp. 33-40. Copyright (C) 1999 Kluwer Academic Publishers. Used by permission. http://www.springerlink.com/content/102965/

\title{
Biochemical and biophysical analysis of the intracellular lipid binding proteins of adipocytes
}

\author{
Melanie A. Simpson, Vince J. LiCata, Natalie Ribarik Coe and David A. Bernlohr \\ Department of Biochemistry, University of Minnesota, St. Paul, MN, USA
}

\begin{abstract}
Adipocytes express two lipid-binding proteins; the major one termed the adipocyte lipid-binding protein or aP2 (ALBP/aP2) and a minor one referred to as the keratinocyte lipid-binding protein (KLBP). In order to evaluate the potential physiological roles for these proteins, their biochemical and biophysical properties have been analyzed and compared. ALBP/aP2 and KLBP exhibit similar binding affinities for most long-chain fatty acids; however, ALBP/aP2 exhibits a two to three-fold increased affinity for myristic, palmitic, oleic and linoleic acids, the predominant fatty acids of adipocytes. As measured by guanidinium hydrochloride denaturation, the stability of ALBP/aP2 is nearly $3 \mathrm{kcal} / \mathrm{mol}$ greater than that of KLBP. While the $\mathrm{pI}$ of ALBP/ aP2 was determined to be 9.0, that of KLBP is 6.5 suggesting differing net charges at physiological $\mathrm{pH}$. Analysis of surface electrostatic properties of ALBP/aP2 and KLBP revealed similar charge polarity, although differences in the detailed charge distribution exist between the proteins. The distribution of hydrophobic patches was also different between the proteins, ALBP/aP2 has only scattered hydrophobic surfaces while KLBP has a large hydrophobic patch near the ligand portal into the binding cavity. In sum, these results point out that despite the striking similarity between ALBP/aP2 and KLBP in tertiary structure, significant differences in ligand binding and surface properties exist between the two proteins. Hence, while it is tempting to speculate that $\mathrm{ALBP} / \mathrm{aP} 2$ and KLBP are metabolically interchangeable, careful analysis suggests that the two proteins are quite distinct and likely to play unique metabolic roles.
\end{abstract}

Keywords: fatty acids, adipocytes, binding proteins, electrostatics

\section{Introduction}

Lipid-binding proteins (LBPs) are small, abundantly distributed, cytosolic polypeptides which bind hydrophobic ligands [for reviews see [1-3]. Over 20 different LBP family members have been identified in vertebrates alone. Although named frequently for the tissue from which they were initially isolated, most LBPs are expressed in several cell or tissue types, and any given tissue may express multiple LBPs. Crystal structures have revealed that members of the family share a superimposable tertiary structure despite having primary sequence identity that varies from 20 $70 \%$. The tertiary structure is characterized by a flattened ten-stranded b-barrel that encompasses a water-filled internal ligand-binding cavity secluded from solvent by a somewhat flexible helix-turn-helix cap. Despite their relative abundance, solubility, ease of purification, and a wealth of structural data, the specific physiological functions of these proteins are unknown. The presence of a LBP in lipid metabolizing tissues is likely necessitated by cellular demand for fatty acids at a level beyond their inherent cytosolic solubility. This is especially true in adipocytes, where massive fluxing of lipids occurs continually.

The adipocyte member of the LBP family (ALBP or $\mathrm{aP} 2$ ) is found exclusively in adipocytes or adipogenic cell lines and was, until recently, thought to be the only LBP in fat cells. It has since been shown that murine adipocytes express a minor LBP, the keratinocyte lipid-binding protein (KLBP) as well, albeit at very low levels relative to ALBP/aP2 (approximately $1 \%$ of ALBP/aP2 protein levels) [4]. KLBP was originally identified as an over-expressed mRNA in murine squamous cell carcinomas and 
other transformed skin lines [5, 6]. Examination of adipose tissue from transgenic mice null for ALBP/aP2 revealed that when ALBP/aP2 is not expressed, KLBP becomes significantly upregulated. However, neither protein nor message levels of KLBP achieve the concentration of ALBP/ aP2 in normal adipocytes [4].

Initial characterization of $\mathrm{ALBP} / \mathrm{aP} 2$ null mice on a standard lab chow diet containing $4 \%$ fat demonstrated few metabolic abnormalities. Hence, it was speculated, KLBP must function so similarly within the adipocyte that it is able to compensate on a molecular level for the loss of ALBP/aP2. However, a strikingly different interpretation arose when ALBP/aP2 null mice were maintained on a high fat diet. Hotamisligil et al., observed that although there were no obvious outward phenotypic differences, the ALBP/aP2 mice failed to develop obesityrelated non insulin dependent diabetes mellitus [7]. That is, when fed a diet high in fat ( $40 \%$ of calories from fat), wild type mice became somewhat obese, hyperglycemic, hyperinsulinemic, and responded poorly to insulin or glucose tolerance tests. In contrast, $\mathrm{ALBP} / \mathrm{aP} 2$ null mice became quite obese, but maintained low circulating levels of insulin and glucose, and responded well to insulin or glucose tolerance tests. Relative expression levels of several other adipocyte mRNAs, including enzymes involved in fat cell lipid metabolism, were unchanged, suggesting that essential fat cell metabolism was largely unaltered by the ALBP/aP2 null status. However, whereas obese wild type mice expressed high levels of tumor necrosis factor $\alpha(\mathrm{TNF} \alpha)$, neither lean wild type nor obese ALBP/aP2 disrupted mice harbored significant quantities of this diabetes-associated cytokine.

Ribarik Coe et al. [4], further observed that the efflux of fatty acids from adipocytes of null mice was impaired relative to wild type and that free fatty acids were elevated in such nulls. Together these findings suggest severe alterations in lipid trafficking resulting from loss of ALBP/aP2 expression. Since adipocytes express more than one lipidbinding protein, the failure to develop obesity-linked noninsulin dependent diabetes mellitus could derive from loss of ALBP/aP2 and/ or increase in KLBP. Altered efflux efficacy and subsequent accumulation of fatty acids could result from less productive interaction between KLBP and cytoplasmic lipids. Alternatively, metabolic abnormalities may arise due to inefficient interactions between KLBP and intracellular proteins or membranes. Differences in the mechanism of ligand transfer from protein to phospholipid vesicles have been documented between LBPs, and in some cases, have been attributed to specific charged residues [8-11]. These observations have prompted us to explore the biochemical and biophysical characteristics of the two proteins.
We present here a detailed comparison of the intrinsic biochemical, ligand-binding, and electrostatic properties of ALBP/aP2 and KLBP. Although binding properties are very similar, there are notable differences. Additionally, the proteins were found to have significantly different isoelectric points, surface properties, and chemical stabilities. We discuss these differences within the context of altered lipolytic capacities in ALBP/aP2-disrupted mice and speculate about implications for non-insulin dependent diabetes mellitus.

\section{Materials and methods}

\section{Purification of ALBP/aP2 and KLBP protein}

Recombinant proteins were expressed in E. coli and purified essentially as described [12]. Briefly, both purifications employ $\mathrm{pH} 5$ acetate precipitation and gel filtration chromatography. Following gel filtration, ALBP/aP2 or KLBP is loaded on a BioS anion exchange column (BioRad) in 50 $\mathrm{mM} \mathrm{NaOAc}$ at $\mathrm{pH} 5.2$ and eluted with a gradient of $0-1 \mathrm{M}$ $\mathrm{NaCl}$ (ALBP/aP2) or $0-0.6 \mathrm{M} \mathrm{NaCl}$ (KLBP) in $50 \mathrm{mM} \mathrm{ac}-$ etate ( $\mathrm{pH}$ 5.2).

\section{Isoelectric focusing of $A L B P / a P 2$ and $K L B P$}

Standard two-dimensional electrophoresis techniques were employed to determine the isoelectric points of ALBP and KLBP. Isoelectric focusing calibration markers ( $\mathrm{pI}$ range $3-10$, Pharmacia) in the presence and/or absence of $20 \mu \mathrm{g}$ of purified KLBP were run in an acrylamide $(5.5 \%)$ vertical tube gel $\left(400 \mathrm{~V}, 4^{\circ} \mathrm{C}, 18 \mathrm{~h}\right)$ from basic (sodium hydroxide) to acidic conditions (13 mM phosphoric acid). $40 \mu \mathrm{g}$ of purified ALBP/aP2 was run in a denaturing acrylamide tube gel $(8.4 \%$ acrylamide, $9.25 \mathrm{M}$ urea, $4 \%$ Nonidet P$40)$ under identical conditions. The resulting tube gels were analyzed in the second dimension by SDS-PAGE $(12.5 \%$ acrylamide).

\section{1,8-ANS binding and competition assays}

In vitro binding data for various putative ligands of ALBP/ aP2 or KLBP were measured by displacement of LBPbound 1-anilinonaphthalene-8-sulfonic acid (1,8-ANS) as previously described [13]. Briefly, increasing competitor ligand concentrations were added to ANS-bound LBP $([\mathrm{ANS}]=500 \mathrm{nM},[\mathrm{ALBP}]=540 \mathrm{nM},[\mathrm{KLBP}]=390 \mathrm{nM})$ in $50 \mathrm{mM} \mathrm{NaPO}$ ( $\mathrm{pH}$ 7.4). The decrease in fluorescence was plotted as a function of competitor concentration and used to calculate competitor constants. Excitation and emission wavelengths were 368 and $465 \mathrm{~nm}$, respectively, for ANS/ALBP or 375 and $473 \mathrm{~nm}$ for ANS/KLBP. 
Stability of ALBP/aP2 and KLBP proteins

Relative stability of ALBP/aP2 and KLBP was assessed by monitoring the shift in maximum tryptophan emission wavelength as a function of increasing guanidine $\mathrm{HCl}$ concentration as previously described [14]. Denaturation curves were analyzed to determine $\mathrm{Cm}$, the concentration of guanidine $\mathrm{HCl}$ at $50 \%$ denaturation, and free energies of unfolding were calculated by the linear extrapolation method of Pace [15].

\section{Electrostatic and hydrophobic surfaces of $A L B P / a P 2$ and $K L B P$}

Crystal coordinates for ALBP/aP2 were used to model its surface electrostatics (Brookhaven Protein Data Bank code 1LIB). The crystal structure for KLBP is not yet available so it was modeled using Swiss-Model, an automated modeling package implemented by internet (http://www.expasy. hcuge.ch/swissmod/SWISS-MODEL.html) $[16,17]$. KLBP was modeled on the basis of its similarity to homologous structures existing in the Brookhaven Protein Data Bank: 10PA (apo cellular retinol binding protein II), 1ADL (ALBP/ aP2-arachidonate), 1AB0 (C1G, V32D, F57H apoALBP, crystallized at $\mathrm{pH} 4.5), 1 \mathrm{ACD}(\mathrm{C} 1 \mathrm{G}, \mathrm{V} 32 \mathrm{D}$, F57H apoALBP, crystallized at $\mathrm{pH}$ 6.4), 1PMP (myelin P2 protein), 1HMR (HFABP-elaidic acid), 1CBI (cellular retinoic acid binding protein I), and 1CBQ (cellular retinoic acid binding protein II). After primary modeling, the structure was energy minimized using CHARMm. Hydrogen atoms were added to structures using Insight II (Biosym, Inc.). Electrostatic calculations were carried out with the program GRASP [ 18]. Program defaults were used for all adjustable parameters except ionic strength, which was set at $0.145 \mathrm{M}$. Electrostatic potential contours shown were generated with GRASP. Hydrophobic residue distributions were generated with the program Rasmol [19].

Table 1. General properties of ALBP/aP2 and KLBP.

$\begin{array}{lll}\text { Property } & \text { ALBP/aP2 } & \text { KLBP } \\ \text { number of amino acids } & 131 & 135 \\ \text { molecular mass (Da) } & 14,578 & 15,137 \\ \text { tissue distribution } & \text { adipose } & \text { skin, adipose, lens } \\ & & \text { epithelium } \\ \text { relative abundance in fat } & 60 \mathrm{mg} / \mathrm{g} \text { total } & 0.6 \mathrm{mg} / \mathrm{g} \text { total } \\ & \text { fat protein } & \text { fat protein } \\ \text { pI (predicted/experimental) } & 8.55 / \approx 9 & 6.14 / \approx 6.5\end{array}$

Molecular masses and predicted isoelectric points were obtained from the internet SwissModel server (http://expasy.hcuge.ch/swissmod/SWISSMODEL.html). Empirical isoelectric points were estimated by comparison with standards on isoelectric focusing gels as illustrated in Figure 2.

\section{Results}

To explore the potential molecular mechanisms by which ALBP/aP2 and KLBP could impact fat cell metabolism, several biochemical and biophysical properties of ALBP/ aP2 and KLBP were compared. Table 1 summarizes the molecular weights, tissue distributions $[5,20]$, and relative abundances in adipose [4]. ALBP/aP2 and KLBP are found in very different tissues, which might imply different functions for the proteins (ALBP/aP2 in adipose exclusively, KLBP low in intestine and kidney, some in heart, brain, liver, spleen, muscle, lung, adipose, mammary, and lens/ tongue/epidermal epithelial cells). ALBP/aP2 is extremely abundant in adipocytes, constituting $1-5 \%$ of total soluble protein, whereas KLBP levels are about $1 \%$ those of ALBP/aP2. Relative abundance in adipose may be related to metabolic role; however, identification of functional differences between ALBP/aP2 and KLBP in adipose cells is more likely to occur through comparative ligand binding analysis. Richieri et al. have reported a systematic ligandbinding comparison between several lipid-binding proteins which demonstrated significant variability in both affinities and specificities [21]. We present here a comparative study of in vitro ligand-binding properties of ALBP/aP2 and KLBP.

Table 2 summarizes binding studies comparing affinities of ALBP/aP2 and KLBP for potential fatty acid ligands, fatty

Table 2. In vitro binding of putative ligands by ALBP and KLBP

\begin{tabular}{llll} 
Ligand & & ALBP & KLBP \\
\hline decanoate & $10: 0$ & $2800 \pm 400$ & 4300 \\
myristate & $14: 0$ & $506 \pm 63$ & $1873 \pm 489$ \\
palmitate & $16: 0$ & $390 \pm 30$ & $1087 \pm 63$ \\
oleate & $18: 1$ & $215 \pm 20$ & $320 \pm 11$ \\
linoleate & $18: 2$ & $368 \pm 1$ & $499 \pm 40$ \\
linolenate & $18: 3$ & $553 \pm 8$ & $495 \pm 28$ \\
arachidonate & $20: 4$ & $284 \pm 21$ & $412 \pm 4$ \\
docosahexaenoate & $22: 6$ & $198 \pm 22$ & 450 \\
5-HPETE & $20: 4$ & $317 \pm 31$ & $1100 \pm 200$ \\
15-HPETE & $20: 4$ & 412 & $600 \pm 240$ \\
homogamma linolenate & $20: 3$ & $832 \pm 24$ & $219 \pm 6$ \\
eicosatrienoate & $20: 3$ & $655 \pm 17$ & $186 \pm 18$ \\
conjugated linoleate & $18: 2$ & $149 \pm 7$ & $204 \pm 14$ \\
15-deoxy- $\Delta$ 12,14-PGJ2 & & $1910 \pm 110$ & $>10,000$ \\
LY-171883 & & 2100 & $1860 \pm 800$ \\
Wy-14643 & & $\approx 10,000$ & $\approx 10,000$
\end{tabular}

In vitro binding data for various putative ligands of ALBP or KLBP were measured by displacement of 1-anilinonaphthalene-8-sulfonic acid (1,8-ANS) as described in Materials and methods. Briefly, increasing competitor ligand concentrations were added to protein and bound ANS in $50 \mathrm{mM} \mathrm{NaPO}_{4}(\mathrm{pH}$ 7.4). Excitation and emission wavelengths for ANS/ ALBP were 368 and 465 $\mathrm{nm}$, respectively. Corresponding wavelengths used for ANS/KLBP were 375 and 473. The decrease in fluorescence was plotted as a function of competitor concentration and used to calculate competitor constants. 
acid analogs and several other lipids. Lipid competitor constants were measured based upon each ligand's ability to compete with the fluorescent probe 1-anilinonaphthalene8sulfonic acid for binding to ALBP/aP2 or KLBP. Affinities and specificities show few major differences, except for oleate, myristate, palmitate, and linoleate, all of which showed 2-3 fold lower affinity for KLBP than for ALBP/ aP2. Since these are major constituents of the cellular fatty acid pool, a two-fold difference might affect the metabolic availability of substrate in ALBP/aP2 nulls relative to wild type cells.

The low levels of KLBP expression in adipose tissue relative to $\mathrm{ALBP} / \mathrm{aP} 2$ prompted a comparison of the relative chemical stabilities of the two proteins. Shifts in tryptophan emission maxima resulting from denaturation were plotted as a function of denaturant concentration. Figure 1 illustrates a dramatic difference in the midpoint of the denaturation curve for KLBP vs. ALBP/aP2, which translates to a free energy of unfolding almost $3 \mathrm{kcal} / \mathrm{mol}$ lower for KLBP than for ALBP $/ \mathrm{aP} 2(\Delta \mathrm{G}=-2.3 \mathrm{kcal} / \mathrm{mol}$ for KLBP vs. $\Delta \mathrm{G}=-5.3 \mathrm{kcal} / \mathrm{mol}$ for ALBP). Hence, the relatively low intracellular levels of KLBP may be partially determined by intrinsic stability. This is supported by the observation that KLBP message levels in aP2 disrupted mice are elevated 40-fold relative to wild type, whereas steady state protein levels are only about 7-fold higher.

Storch and colleagues have demonstrated that collisional transfer of fatty acids from LBPs to phospholipid vesicles is dependent upon phospholipid charge composition $[8,9]$. Specific positively charged residues in ALBP/aP2 and

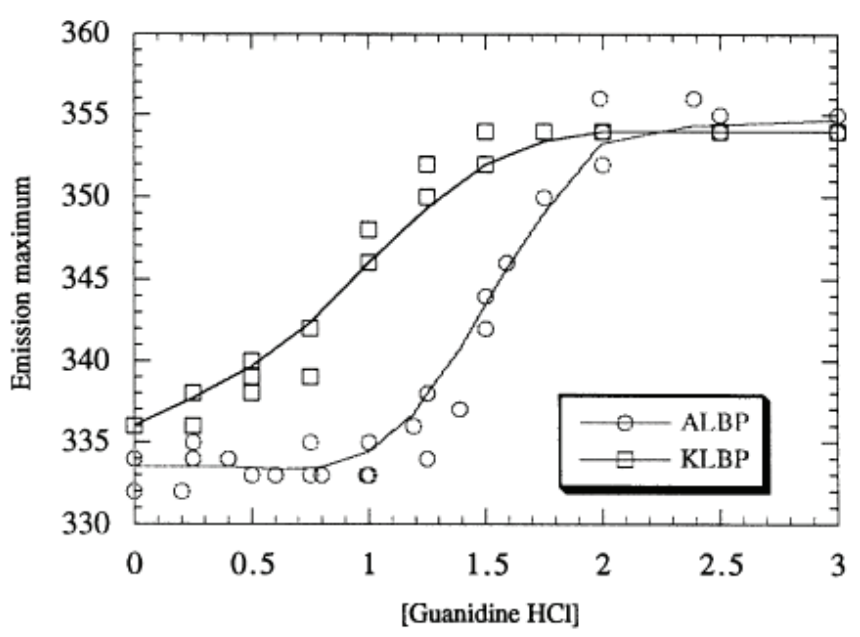

Figure 1. Guanidine $\mathrm{HCl}$ denaturation of ALBP and KLBP. Relative stability of ALBP and KLBP was assessed by monitoring the shift in maximum tryptophan emission wavelength as a function of increasing guanidine $\mathrm{HCl}$ concentration as described in Materials and methods. Denaturation curves were fitted to determine $\mathrm{Cm}$, the concentration of guanidine $\mathrm{HCl}$ at $50 \%$ denaturation, and free energies of unfolding were calculated as described.
HFABP may mediate this dependence $[10,11]$. While information on KLBP interaction with membrane vesicles is not available, potential explanations for membrane interaction specificity between LBPs include: (1) specific surface charge location; (2) overall protein charge density and (3) altered surface charge distribution. To analyze possible interactive differences between ALBP/aP2 and KLBP and membranes, we examined the electrostatic properties of ALBP/aP2 and KLBP. As presented in Figure 2, isoelectric focusing resolved net charge differences between ALBP/aP2 and KLBP. ALBP/aP2 has a pI of about 9.0, whereas KLBP has a pI of about 6.5. Hence at intracellular $\mathrm{pH}, \mathrm{ALBP} / \mathrm{aP} 2$ will be more basic than KLBP. The primary sequences of ALBP/aP2 and KLBP are aligned in Figure 3. All surface accessible lysines analogous to those mutagenized and shown to be involved in the transfer mechanism for heart FABP are conserved between ALBP/aP2 and KLBP suggesting that although these might regulate the mechanism of transfer, they probably do not confer any specificity of interaction.

Surface charge and hydrophobic amino acid distributions were examined for potential surface differences that might relate to function (Figure 4A; details of the electrostatics of ALBP will be discussed elsewhere: [28]). Both ALBP/aP2 and KLBP are charge polarized, with positive dipoles for the two proteins oriented out the helixturn-helix cap. The details of the electrostatic distribution differ for the two molecules, however. ALBP/aP2 has a conspicuous positive ridge across the top of the molecule, which is less pronounced in KLBP. Roughly

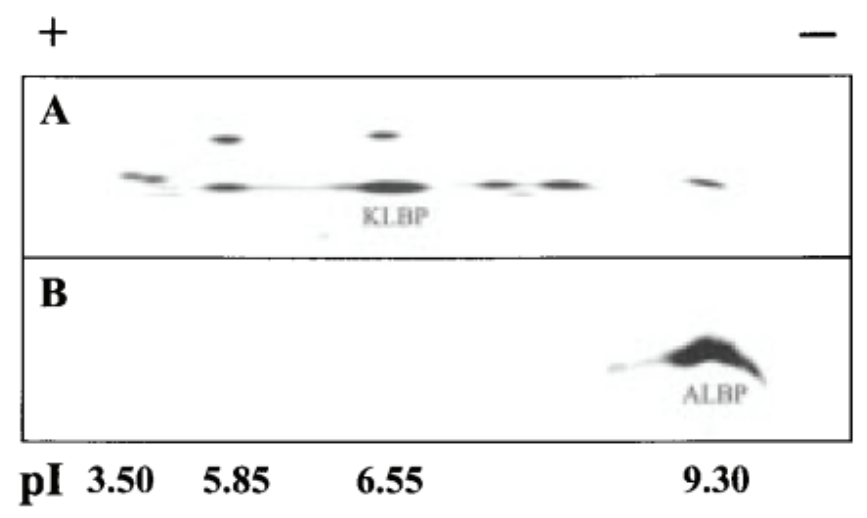

Figure 2. Isoelectric focusing of ALBP and KLBP. (A) Standard isoelectric focusing calibration markers (pI range 3-10, Pharmacia) in the presence and/ or absence of $20 \mu \mathrm{g}$ of purified KLBP were run in an acrylamide vertical tube gel from basic to acidic conditions. The resulting tube gel was analyzed in the second dimension by SDS-PAGE. By comparison with marker $\mathrm{pI}$ values ranging from 3.5 to 9.3 , the $\mathrm{pI}$ of KLBP was determined to be approximately 6.5. (B) $40 \mu \mathrm{g}$ of purified ALBP was run in an acrylamideurea tube gel from basic to acidic conditions (first dimension) prior to standard SDS-PAGE analysis (second dimension). The $\mathrm{pI}$ of ALBP under denaturing conditions is approximately 9 . 


\begin{tabular}{|c|c|c|c|c|c|}
\hline & 10 & 20 & 30 & 40 & 50 \\
\hline LBP & ... CDAFVGT & WKLVSSENFD & DYMKEVGVGF & ATRKVAGMAK & PNMI I SVNGD \\
\hline \multirow[t]{2}{*}{ KLBP } & MASLKDLEGK & WRLMESHGFE & EYMKELGVGL & ALRKMAAMAK & PDCIITCDGN \\
\hline & 60 & 70 & 80 & 90 & 100 \\
\hline & LVTIRSESTF & KNTEISFKLG & VEFDEITADD & RKVKSIITLD & GGALVQVQKW \\
\hline \multirow[t]{2}{*}{$\begin{array}{l}\text { KLBP } \\
\text { KLB }\end{array}$} & NITVKTESTV & KTTVFSCNLG & EKFDETTADG & RKTETVCTFQ & DGALVQHQOW \\
\hline & $\underset{*}{110}$ & * 120 & 130 & 135 & Ref \\
\hline ALBP & DGKSTTIKRK & RDGDKLVVEC & VMKGVTSTRV & YERA. & [27] \\
\hline KLBP & DGKESTITRK & LKDGKMIVEC & VMNNATCTRV & YEKVQ & [5] \\
\hline
\end{tabular}

Figure 3. Primary sequence alignment of murine ALBP and KLBP. Published cDNA sequences were translated and aligned using GCG program defaults. ALBP surface lysine residues are designated with an asterisk [26]. Those surface lysines analogous to site-specifically mutagenized residues in HFABP [11] as discussed in the text are denoted by a dagger.

corresponding areas of positive and negative potential exist in all views of the two molecules, but KLBP shows consistently smaller positive patches and larger negative patches. These differences will contribute to interactions between the two proteins and any potential partner, although the corresponding patterns suggest that the two proteins may be able to interact electrostatically with the same partners but with different affinities.

Comparison of the hydrophobic surfaces of the two proteins also reveals some potentially pertinent differences (Figure 4B). Hydrophobic residues are nearly randomly distributed over the surface of ALBP/aP2, with no obvious large patches. KLBP, however, has a relatively large hydrophobic patch near the top of the molecule, on the portal or front face. Overall, the distribution of hydrophobic residues in KLBP is more patchy or clustered, while ALBP/ aP2's surface hydrophobicity is more dispersed, lending strength to a model of $\mathrm{ALBP} / \mathrm{aP} 2$ and $\mathrm{KLBP}$ interacting differentially.

\section{Discussion}

Despite intensive scrutiny from diverse experimental angles, it has remained difficult to assign a particular function to any of the LBPs (though several recent reviews thoroughly discuss possibilities, [1-3]). ALBP/aP2 null mice have afforded another opportunity to ask physiological questions. Because ALBP/aP2 is specifically expressed in adipose, disruption of its gene should have distinct and measurable effects. The loss of ALBP/aP2 is partially compensated on a molecular level by the upregulation of KLBP $[4,7]$, a lipid-binding protein normally found in epithelial-type cells. Although the phenotypes of wild type and ALBP/aP2 null mice are virtually identical on a diet of standard lab chow, important metabolic differences exist between the two strains which become more dramatic on a diet which stresses the adipocyte [7]. Unlike their wild type counterparts, null mice have higher free fatty acid levels [4], lower resting and stimulated lipolytic rates [4], and fail to become insulin resistant when fed a diet high in fat [7]. These differences prompted a systematic comparison of the biochemical properties of ALBP/aP2 and KLBP.

Table 2 summarizes dissociation constants for ALBP/ aP2 and KLBP binding to a series of potential physiological ligands. While similar constants are observed in most cases, binding of oleate, palmitate, linoleate, and myristate differed by $2-3$ fold. Interestingly, analysis of the free fatty acid composition of adipocytes from wild type or ALBP/ aP2 disrupted mice revealed 2-3 fold increases in the levels of those fatty acids [4], perhaps resulting from an inability of KLBP to direct them appropriately for metabolism. Denaturation of the two proteins reveals inherent differences in stability. Northern analysis demonstrated 40-fold upregulation of KLBP message in nulls relative to wild type while protein levels only rose 7-fold [4], leading to significantly diminished total LBP levels in nulls. This discrepancy may be the result of the reduced intrinsic stability of KLBP. Furthermore, the isoelectric points for the two proteins are quite different, as are the patterns of surface charges and hydrophobic patches.

LBPs are frequently hypothesized to serve either as passive providers of fatty acid buffering capacity to the aqueous cytosol, in which lipids are poorly soluble, or as more active fatty acid chaperones, responsible for trafficking of lipids between various intracellular locales. Lipids may exist at low levels free in the cytosol, but non-esterified fatty acid concentrations in adipocytes are many fold higher [4] than in vitro solubility measurements would suggest possible [22]. Fatty acids may additionally equilibrate within the plasma membrane, various organelle membranes, or the surface of the triglyceride droplet, but elevated levels will exert a disruptive micellar effect on membranes and proteins. Hence, it has often been proposed that the purpose of the abundant LBPs in lipid-active tissues is to permit free fatty acids to exist at appropriate metabolic levels within the cell while preventing the deleterious effects of such high concentrations.

LBP overexpression has been shown to facilitate cellular uptake of exogenously added fatty acids and dispersion among organelles [23, 24]. One might predict, therefore, that total nonesterified fatty acid levels would decrease in proportion to a decrease in LBP concentration. However, ALBP/aP2 null mice seem to contradict this supposition. The concentration of nonesterified fatty acid is inversely proportional to the level of LBP [4]. If ALBP/aP2 were simply a buffer for fatty acids, merely sequestering and solubilizing them, transgenic mice should have lower nonesterified fatty acid levels than wild type, since the overall LBP concentration is lower. In this case, elevation of fatty acids would saturate the buffering capacity of the LBP pool, leading to product inhibition of hormone-sensitive li- 

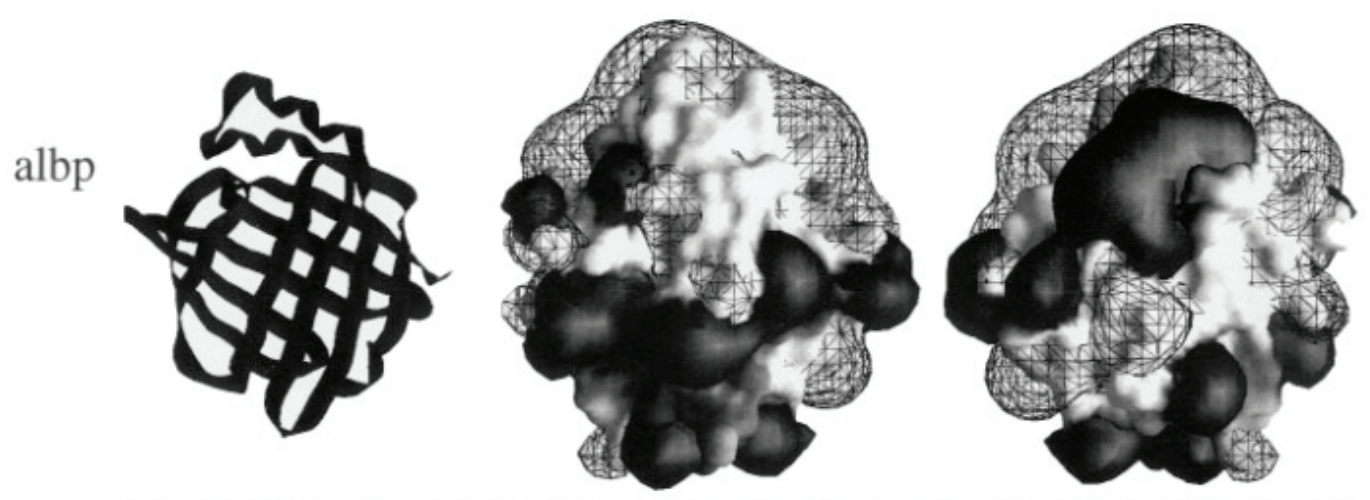

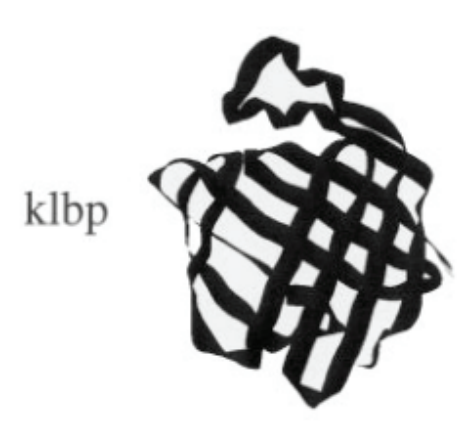

"front" views
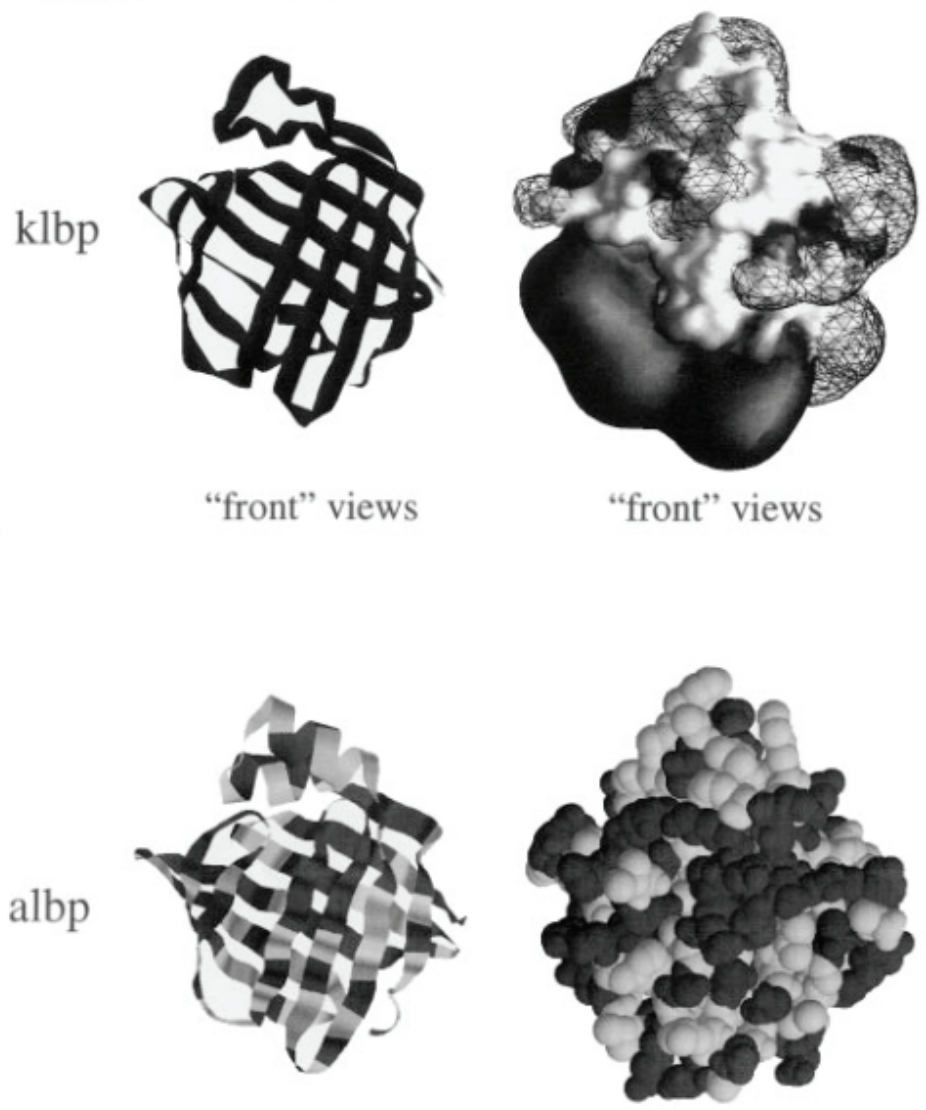

"front" views

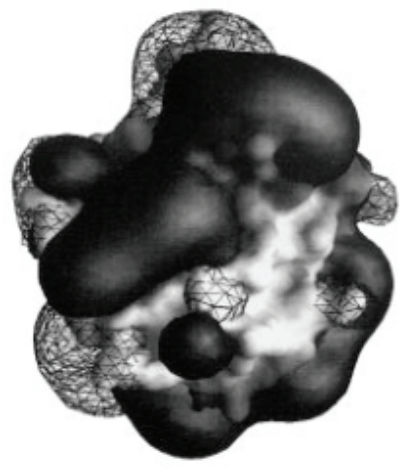

"back" views

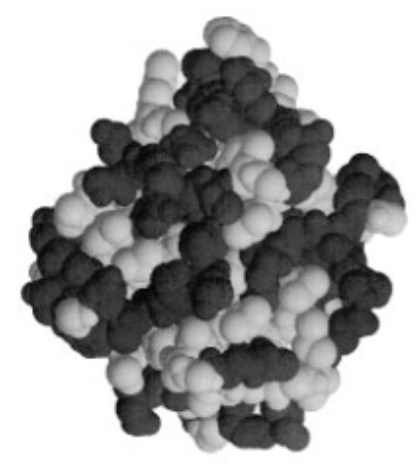

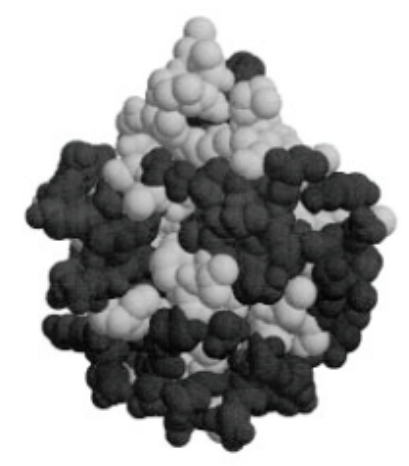

"front" views

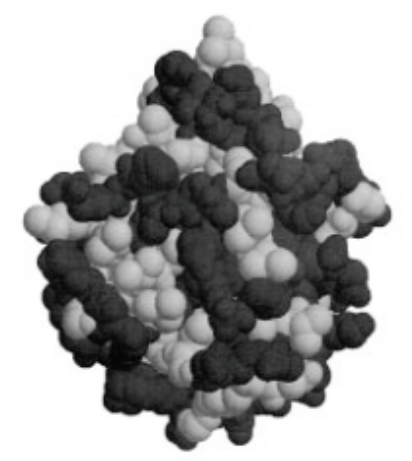

"back" views 
pase and decreased liberation of fatty acids from lipolysis. Lipolysis in ALBP/aP2 null mice is compromised in both resting and catecholamine-stimulated adipocytes [4], but because stimulation is equally effective in both types of adipocytes, product inhibition of hormone-sensitive lipase is unlikely to be the causative agent. This line of reasoning leads to a model in which ALBP/aP2 is an active shuttle of lipids, whose specific intracellular interactions are required for efflux of fatty acids. ALBP/aP2 is 55\% identical and $70 \%$ similar to KLBP; the differences in overall charge and surface charge distribution could determine the unique interactions of the two proteins, particularly in lipolysis.

Storch and colleagues have examined the mechanisms of ligand transfer from LBPs to synthetic membranes. In a fluorescence assay designed to measure kinetics of fatty acid dissociation, ALBP/aP2 transferred bound fluorescent fatty acid analogs to phospholipid vesicles in a concentration dependent manner [8]. This implies that dissociation of lipids from ALBP/aP2 occurs preferentially through collision with vesicles rather than by random diffusion. In diffusional transfer, as in the case of liver FABP [25], fatty acid dissociation from the LBP would precede its insertion in the phospholipid vesicle, the kinetics of which would not change with vesicle concentration. The rate of collisional transfer from ALBP/aP2 was further shown to be dependent upon surface electrostatic interactions $[9,10]$. ALBP/ aP2 has several lysine residues near the site of ligand entry/exit (the portal). Transfer was found to occur more rapidly to vesicles containing a higher fraction of negatively charged, rather than predominantly neutral or positively charged, phospholipids. When all surface lysines were neutralized by acetylation, the mechanism of transfer became diffusional, regardless of phospholipid composition. We can speculate that KLBP, on the basis of its lower pI (6.5) and its differing electrostatic contour distribution, may transfer fatty acids at rates distinctly different from ALBP/aP2. Comparison of ALBP/aP2 and KLBP transfer rates may help address the importance of specific lysines vs. overall charge or charge distribution.

Figure 4. Electrostatic and hydrophobic surfaces of ALBP and KLBP. Crystal structure coordinates were used for ALBP (PDB code 1LIB). The crystal structure for KLBP is not yet available so it was modeled using the SwissModel internet modeling facility. KLBP was modeled on the basis of its similarity to eight structurally homologous templates existing in the Brookhaven Protein Data Bank: five fatty acid-binding proteins, two retinoic acid-binding proteins, and one retinol-binding protein. (A). Top panel. Electrostatic calculations were carried out with the program GRASP. Electrostatic potential contours shown were generated with GRASP. Negative potential is displayed as dark gray, positive as wire mesh, and neutral in white. (B). Lower panel. Hydrophobic residue distributions were generated with the program Rasmol. Lighter regions show non-polar residues; darker residues are polar.
In conclusion, metabolic dysfunction exhibited by the ALBP/aP2 knock-out mouse model has underscored the importance of lipid-binding proteins in intracellular lipid trafficking. The biochemical and biophysical analyses described in this study characterize ALBP/aP2 and KLBP as separate and distinct members of the LBP multigene family. While it is tempting to conclude that the upregulation of KLBP in ALBP/aP2 null mice is an example of molecular compensation, careful analysis reveals that the properties of KLBP are not identical to those of ALBP/aP2. A more comprehensive understanding of those differences may provide clues to the role of fatty acids in the development of non-insulin dependent diabetes mellitus.

\section{Acknowledgments}

The authors would like to thank the members of the Bernlohr laboratory for helpful discussions during the preparation of this manuscript. This work supported by NSF MCB 9506088 to DAB.

\section{References}

1. Banaszak LJ, Winter N, Xu Z, Bernlohr DA, Cowan S, Jones TA: Lipid-binding proteins: a family of fatty acid and retinoid transport proteins. Adv Prot Chem 45: 89-151, 1994

2. Bernlohr DA, Simpson MA, Hertzel AV, Banaszak LJ: Intracellular lipid-binding proteins and their genes. Annu Rev Nutr 17: 277-303, 1997

3. Veerkamp JH, Maatman RGHJ: Cytoplasmic fatty acid-binding proteins: Their structure and genes. Prog Lipid Res 34: 17-52, 1995

4. Ribarik Coe N, Simpson MA, Johnston Smith A, Bernlohr DA: Targeted disruption of the adipocyte lipid binding protein impairs fat cell lipolysis and increases cellular fatty acid levels. J Biol Chem, submitted

5. Krieg P, Feil S, Furstenberger G, Bowden GT: Tumor-specific overexpression of a novel keratinocte lipid-binding protein: Identification and characterization of a cloned sequence activated during multistage carcinogenesis in mouse skin. J Biol Chem 238: $17362-17369,1993$

6. Kane CD, Ribarik Coe N, Vanlandingham B, Krieg P, Bernlohr DA: Expression, purification, and ligand-binding analysis of recombinant keratinocyte lipid-binding protein (MAL-1), an intracellular lipid-binding protein found overexpressed in neoplastic skin cells. Biochemistry 35: 2894-2900, 1996

7. Hotamisligil GS, Johnson RS, Distel RJ, Ellis R, Papaioannou VE, Spiegelman BM: Uncoupling of obesity from insulin resistance through a targeted mutation in aP2, the adipocyte fatty acid binding protein. Science 274: 1377-1379, 1996

8. Wootan MG, Bernlohr DA, Storch J: Mechanism of fluorescent fatty acid transfer from adipocyte fatty acid binding protein to membranes. Biochemistry 32: 8622-8627, 1993 
9. Wootan MG, Storch J: Regulation of fluorescent fatty acid transfer from adipocyte and heart fatty acid binding proteins by acceptor membrane lipid composition and structure. J Biol Chem 269: 10517-10523, 1994

10. Herr FM, Matarese V, Bernlohr DA, Storch J: Surface lysine residues modulate the collisional transfer of fatty acid from adipocyte fatty acid binding protein to membranes. Biochemistry 34 : 11840-11845, 1995

11. Herr FM, Aronson J, Storch J: Role of portal region lysine residues in electrostatic interactions between heart fatty acid binding protein and phospholipid membranes. Biochemistry 35: 12961303, 1996

12. Xu Z, Buelt MK, Banaszak U, Bernlohr DA: Expression, purification, and crystallization of the adipocyte lipid binding protein. J Biol Chem 266: 14367-14370, 1991

13. Kane CD, Bernlohr DA: A simple assay for intracellular lipidbinding proteins using displacement of 1-anilinonaphthalene-8sulfonic acid. Anal Biochem 233: 197-204, 1996

14. Buelt MK, Xu Z, Banaszak W, Bernlohr DA: Structural and functional characterization of the phosphorylated adipocyte lipidbinding protein (pp 15). Biochemistry 31: 3493-3499, 1992

15. Pace CN: The stability of globular proteins. Crit Rev Biochem 3: $1-43,1975$

16. Peitsch MC: Protein modeling by E-mail. Bio/Technology 13: 658-660, 1995

17. Peitsch MC: ProMod and Swiss-Model: Internet-based tools for automated comparative protein modelling. Biochem Soc Trans 24: 274-279, 1996

18. Nicholls A, Sharp KA, Honig B: Protein folding and association: Insights from the interfacial and thermodynamic properties of hydrocarbons. Proteins 11: 281-296, 1991
19. Sayle RA, Milner-White EJ: RASMOL: Biomolecular graphics for all. TIBS 20: 374, 1995

20. Bernlohr DA, Doering TL, Kelly U Jr, Lane MD: Tissue specific expression of $\mathrm{p} 422$ protein, a putative lipid carrier, in mouse adipocytes. Biochem Biophys Res Comm 132: 850-855, 1985

21. Richieri GV, Ogata RT, Kleinfeld AM: Equilibrium constants for the binding of fatty acids with fatty acid-binding proteins from adipocyte, intestine, heart, and liver measured with the fluorescent probe ADIFAB. J Biol Chem 269: 23918-23930, 1994

22. Vorum H, Brodersen R, Kragh-Hansen U, Pedersen AO: Solubility of long-chain fatty acids in phosphate buffer at $\mathrm{pH}$ 7.4. Biochim Biophys Acta 1126: 135-142, 1992

23. Prows DR, Murphy EJ, Schroeder F: Intestinal and liver fatty acid binding proteins differentially affect fatty acid uptake and esterification in L-cells. Lipids 30: 907-910, 1995

24. Murphy EJ, Prows DR, Jefferson JR, Schroeder F: Liver fatty acid-binding protein expression in transfected fibroblasts stimulates fatty acid uptake and metabolism. Biochim Biophys Acta Lipids and Lipid Metab 1301: 191-198, 1996

25. Hsu K-T, Storch J: Fatty acid transfer from liver and intestinal fatty acid-binding proteins to membranes occurs by different mechanisms. J Biol Chem 271: 13317-13323, 1996

26. Xu Z, Bernlohr DA, Banamak U: Crystal structure of recombinant murine adipocyte lipid-binding protein. Biochemistry $\mathbf{3 1}$ 3484-3492, 1992

27. Bernlohr DA, Angus CW, Lane MD, Bolanowski MA, Kelly U Jr: Expression of specific mRNAs during adipose differentiation: Identification of an mRNA encoding a homologue of myelin P2 protein. Proc Natl Acad Sci USA 81: 5468-5472, 1984

28. LiCata VJ, Bernlohr DA: Surface properties of adipocyte lipid binding protein. Response to lipid binding and comparison with homologous proteins. Proteins (in press) 